\title{
Bizi-ziklo analisiaren irismenaren optimizazioa eraikinen birgaitze energetikoen ingurumen- eta ekonomia-analisietan
}

\author{
(Optimization of life-cycle boundaries for environmental \\ and economic assessment of building energy refurbishment \\ assessments)
}

\author{
Xabat Oregi ${ }^{1 *}$, Maitane Otaño ${ }^{1}$, Patxi Hernandez ${ }^{1}$, Rufino Hernandez ${ }^{2}$ \\ ${ }^{1}$ Tecnalia Research \& Innovation, Azpeitia, Spain. \\ ${ }^{2}$ University of the Basque Country/Architecture, Donostia, Spain. \\ *xabat.oregi@tecnalia.com
}

DOI: $10.1387 /$ ekaia.17650

Laburpena: Eraikuntza-sektorerako bizi-ziklo analisiaren metodologia estandarizatu arren, ikertzaileek sistemaren irismenaren inguruan sinplifikazio batzuk aplikatzeko joera dute bizi-zikloaren fase batzuk alde batera utziz. Birgaitze energetikoetan, erabilera-etapan jartzen da arreta bereziki, energiaren erabilera murriztea baita birgaitze horien helburu nagusia. Artikulu honek etxebizitzen birgaitze energetikoko proiektuetan, ingurumen- eta ekonomia-inpaktu orokorrarekin alderatuta, bizi-zikloko etapa bakoitzaren garrantzia ebaluatzen du. Azterketa kasuko birgaitze-estrategien analisiaren emaitzen arabera, garraio- eta deuseztatze-etapek garrantzi txikia dutela ikusten da. Eraikuntzaprozesuaren etapak ere garrantzi txikia du ingurumen-azterketan. Ekoizpen-, mantentzeeta ordezkatze-etapek, oro har, garrantzi handiagoa dute, batez ere, ebaluazio ekonomikorako. Sentsibilitate-analisi zabal batek bizi-zikloaren mugak sinplifikatzeak dakartzan zailtasunak erakusten ditu, azterketa hauek klima, eraikinaren tipologia, edo aurreikusitako erabilera-bizitza bezalako aldagaiekin duten lotura zuzena azalduz.

Hitz gakoak: eraikinen birgaitze energetikoa, bizi-zikloaren ingurumen- eta ekonomia-analisia, bizi-zikloaren irismena, sentsibilitate-analisia.

Abstract: Despite the standardization of the life-cycle assessment methodology for
the construction sector, analysts tend to apply some simplifications in relation to the
system boundaries, omitting some of the life-cycle stages. In particular, for building
energy refurbishment projects, there is a general focus on the operational stage, linked
to the main objective of reducing operational energy use. This paper evaluates the rele- 
vance of each life-cycle stage in relation to the overall environmental and economic impact on residential building energy refurbishment projects. The results from the analysis of the refurbishment strategies at a case study in Spain show the relatively minor importance of the transport and end of life stages. The construction process stage is also of relatively minor importance regarding the environmental performance. The product, maintenance and replacement stages are generally of higher importance, particularly for economic evaluation. An extensive sensitivity analysis demonstrates the difficulties of simplifying the life-cycle boundaries, suggesting that potential simplifications should take into account various parameters, including the climate region, building typologies, and expected service life.

Keywords: Building energy refurbishment,environmental and economic life-cycle assessment,life-cycle boundaries, sensitivity analysis.

\section{SARRERA}

Eraikuntza-sektorea Europar Batasuneko ingurumenean eragin handienetarikoa duen iturria da, oinarrizko energia-kontsumoaren \% 40aren arduradun delarik [1]. Etxebizitza-sektorearen urteko hazkunde-tasa \% 1 ingurukoa dela ikusirik [2], 2006tik atzera eraiki eta jada birgaitu ez diren eraikinen energia-portaera hobetzeko aukera izugarria dago, birgaitze energetikoa Europar Batasunaren eta nazio-politiken lehentasuna bilakatuz. Birgaitze horietan oinarrituta, eraikinak gero eta energetikoki eraginkorrago bihurtu eta haien erabilera-etaparen inpaktua oso balio baxuetara murriztuko da, bizi-zikloaren beste etapen ingurumen- eta ekonomia-inpaktuen garrantzia handituz. Testuinguru horretan, Europako Batzordeak [3, 4] eta «Bizi-zikloan zehar zero energiako eraikinen» [5] inguruan egindako lanen arabera, bizi-ziklo analisia (BZA) eraikuntza-proiektuen inpaktuak aztertzeko metodologia egokitzat onartua izan da. BZAren metodologia orokorra ISO 14040:1997 [6] eta 14044:1998 [7] arauetan oinarritzen da. Lehen arau horietan oinarrituta, TC/350 [8] edo ISO TC 59/SC17 [9] bezalako Batzorde Teknikoak eraikuntza-sektorerako arautegi bereziak garatzen dabiltza. 1. irudian ikus daitekeen bezala, eraikin baten bizi-ziklo analisiaren irismena eta aztertu beharrezko etapak EN15978:2011 [10] bezalako arautegietan oinarritzen dira.

\begin{tabular}{|c|c|c|c|}
\hline $\begin{array}{l}\text { I. EKOIZPEN ETAPA } \\
\text { A1. Lehengaien } \\
\quad \text { erauzketa eta } \\
\text { prozesaketa } \\
\text { A2. Garraioa } \\
\text { A3. Ekoizpena }\end{array}$ & \begin{tabular}{|l}
\multicolumn{1}{c}{\begin{tabular}{c} 
II. ERAIKUNTZA \\
PROZESUAREN \\
\multicolumn{1}{c}{ ETAPA }
\end{tabular}} \\
A4. Garraioa \\
A5. Eraikuntza- \\
prozesua
\end{tabular} & $\begin{array}{l}\text { III. ERABILERA ETAPA } \\
\text { B1. Erabilera } \\
\text { B2. Mantentzea } \\
\text { B3. Konponketa } \\
\text { B4. Ordezkapena } \\
\text { B5. Birgaitzea } \\
\text { B6. Erabilera etapako } \\
\text { energia-kontsumoa } \\
\text { B7. Erabilera etapako ur- } \\
\text { kontsumoa }\end{array}$ & \begin{tabular}{l}
\multicolumn{1}{c}{$\begin{array}{l}\text { IV. DEUSEZTAPEN } \\
\text { ETAPA }\end{array}$} \\
C1. Eraispena \\
C2. Garraioa \\
C3. Hondakinen \\
kudeaketa \\
C4. Hondakinen \\
deuseztapena
\end{tabular} \\
\hline
\end{tabular}

1. irudia. EN 15978:2011 estandarrean oinarrituriko eraikin baten etapa desberdinak. 
Hala ere, nahiz eta normalizazio-ahaleginak egin izan, 1. taulan bizi-zikloaren etapa guztiak ebaluatzen dituzten azterketa oso gutxi daudela ikus daiteke.

1. taula. Gaur egungo ikerketa-lanen eraikinen bizi-zikloaren etapak.

\begin{tabular}{|c|c|c|c|c|c|c|c|}
\hline & $\mathrm{A} 1-3$ & A4 & A5 & $\mathrm{B} 2$ & B4 & B6 & $\mathrm{C} 1-4$ \\
\hline Zabalza et al., 2009[11] & $\mathrm{X}$ & & & & & $\mathrm{X}$ & \\
\hline Blom et al., 2010 [12] & $\mathrm{X}$ & $\mathrm{X}$ & & $\mathrm{X}$ & $\mathrm{X}$ & $\mathrm{X}$ & $\mathrm{X}$ \\
\hline Blengini \& Di Carlo, 2010 [13] & $\mathrm{X}$ & $\mathrm{X}$ & $\mathrm{X}$ & $\mathrm{X}$ & $\mathrm{X}$ & $\mathrm{X}$ & $\mathrm{X}$ \\
\hline Gustavsoon \&Joelsson, 2010 [14] & $\mathrm{X}$ & $X$ & & & & $\mathrm{X}$ & \\
\hline Hernandez \& Kenny, 2010 [5] & $\mathrm{X}$ & & & & $\mathrm{X}$ & $\mathrm{X}$ & \\
\hline Ortiz et al., 2010 [15] & $\mathrm{X}$ & $\mathrm{X}$ & $\mathrm{X}$ & $\mathrm{X}$ & & $\mathrm{X}$ & $\mathrm{X}$ \\
\hline Dodoo et al., 2010 [16] & $X$ & $\mathrm{X}$ & $\mathrm{X}$ & & & $\mathrm{X}$ & $\mathrm{X}$ \\
\hline Malmqvist et al., 2011 [17] & $\mathrm{X}$ & & & & & $\mathrm{X}$ & \\
\hline Tae et al., 2011 [18] & $\mathrm{X}$ & $\mathrm{X}$ & $\mathrm{X}$ & $X$ & & $\mathrm{X}$ & $\mathrm{X}$ \\
\hline Wallhagen et al., 2011 [19] & $X$ & & & & & $\mathrm{X}$ & \\
\hline Rossi et al., 2012 [20] & $\mathrm{X}$ & $\mathrm{X}$ & & & & $\mathrm{X}$ & \\
\hline Sharma et al., 2012 [21] & $\mathrm{X}$ & $\mathrm{X}$ & & $\mathrm{X}$ & & $\mathrm{X}$ & \\
\hline Gazulla \& Oregi, 2012 [22] & $\mathrm{X}$ & & & & & $\mathrm{X}$ & $\mathrm{X}$ \\
\hline Iyer \& Wong, 2012 [23] & $\mathrm{X}$ & $\mathrm{X}$ & $\mathrm{X}$ & & $\mathrm{X}$ & $\mathrm{X}$ & $\mathrm{X}$ \\
\hline Stephan et al., 2012 [24] & $\mathrm{X}$ & $\mathrm{X}$ & $\mathrm{X}$ & $X$ & $\mathrm{X}$ & $\mathrm{X}$ & \\
\hline Cuellar \& Azapagic, 2012 [25] & $\mathrm{X}$ & $\mathrm{X}$ & $\mathrm{X}$ & $\mathrm{X}$ & $\mathrm{X}$ & $\mathrm{X}$ & $\mathrm{X}$ \\
\hline Ramesh et al., 2012 [26] & $X$ & $\mathrm{X}$ & & & $\mathrm{X}$ & $\mathrm{X}$ & \\
\hline Stephan et al., 2013 [27] & $\mathrm{X}$ & $X$ & $\mathrm{X}$ & $X$ & $\mathrm{X}$ & $\mathrm{X}$ & \\
\hline Asdrubali et al., 2013 [28] & $X$ & $X$ & $\mathrm{X}$ & & $\mathrm{X}$ & $\mathrm{X}$ & $\mathrm{X}$ \\
\hline Allacker \& De Troyer, 2013 [29] & $\mathrm{X}$ & $X$ & $\mathrm{X}$ & $\mathrm{X}$ & $\mathrm{X}$ & $\mathrm{X}$ & $\mathrm{X}$ \\
\hline Paulsen \& Sposto, 2013 [30] & $\mathrm{X}$ & $\mathrm{X}$ & $\mathrm{X}$ & $\mathrm{X}$ & $\mathrm{X}$ & $\mathrm{X}$ & $\mathrm{X}$ \\
\hline Vrijders \& Wastiels, 2013 [31] & $\mathrm{X}$ & $\mathrm{X}$ & $\mathrm{X}$ & $\mathrm{X}$ & $\mathrm{X}$ & $\mathrm{X}$ & \\
\hline De Angelis et al., 2013 [32] & $\mathrm{X}$ & $\mathrm{X}$ & $\mathrm{X}$ & & & $\mathrm{X}$ & $\mathrm{X}$ \\
\hline Ostermeyer et al., 2013 [33] & $\mathrm{X}$ & $\mathrm{X}$ & $\mathrm{X}$ & $\mathrm{X}$ & $\mathrm{X}$ & $\mathrm{X}$ & \\
\hline Mosteiro et al., 2014 [34] & $\mathrm{X}$ & $\mathrm{X}$ & $\mathrm{X}$ & & $\mathrm{X}$ & $\mathrm{X}$ & $\mathrm{X}$ \\
\hline Bull et al., 2014 [35] & $\mathrm{X}$ & & & & $\mathrm{X}$ & $\mathrm{X}$ & $\mathrm{X}$ \\
\hline Dodoo et al., 2014 [36] & $X$ & & $\mathrm{X}$ & & & $\mathrm{X}$ & $\mathrm{X}$ \\
\hline Stephan \& Stephan, 2014 [37] & $\mathrm{X}$ & $X$ & $\mathrm{X}$ & $X$ & $\mathrm{X}$ & $\mathrm{X}$ & \\
\hline Russell-Smith et al., 2014 [38] & $\mathrm{X}$ & $\mathrm{X}$ & $\mathrm{X}$ & & $\mathrm{X}$ & $\mathrm{X}$ & \\
\hline Rodriguez \& Freire, 2014 [39] & $\mathrm{X}$ & $\mathrm{X}$ & $\mathrm{X}$ & $\mathrm{X}$ & $\mathrm{X}$ & $\mathrm{X}$ & $\mathrm{X}$ \\
\hline Bastos et al., 2014 [40] & $\mathrm{X}$ & $\mathrm{X}$ & & $\mathrm{X}$ & $\mathrm{X}$ & $\mathrm{X}$ & \\
\hline Devi \& Palaniappan, 2014 [41] & $\mathrm{X}$ & $\mathrm{X}$ & $\mathrm{X}$ & & & $\mathrm{X}$ & $\mathrm{X}$ \\
\hline Cellura et al., 2014 [42] & $\mathrm{X}$ & $\mathrm{X}$ & $\mathrm{X}$ & & $\mathrm{X}$ & $\mathrm{X}$ & $\mathrm{X}$ \\
\hline Assiego de Larriva et al., 2014 [43] & $\mathrm{X}$ & $\mathrm{X}$ & & & $\mathrm{X}$ & $\mathrm{X}$ & $\mathrm{X}$ \\
\hline Cetiner \& Edis, 2014 [44] & $\mathrm{X}$ & $\mathrm{X}$ & $\mathrm{X}$ & $\mathrm{X}$ & $\mathrm{X}$ & $\mathrm{X}$ & $\mathrm{X}$ \\
\hline Oregi et al., 2015 [45] & $X$ & $X$ & $\mathrm{X}$ & & $\mathrm{X}$ & $\mathrm{X}$ & $\mathrm{X}$ \\
\hline
\end{tabular}


EN15978:2011 [10] eta EN16627:2015 [46] ingurumen- eta ekonomiaarautegietan oinarriturik, artikulu honek bizi-zikloaren etapa bakoitzaren eta birgaituriko eraikinak bere bizi-ziklo osoan zehar erdietsiriko inpaktumurrizketa orokorraren arteko erlazioa landuko du, ingurumen- eta ekonomia-analisietan bizi-ziklo analisiaren irismenaren sinplifikazioak izan dezakeen eragina aztertuz.

\section{AZTERKETA METODOLOGIA ETA HIPOTESIAK}

Atal honek lan honetan zehar erabilitako azterketa- metodologiaren aldagai eta hipotesi nagusiak zehazten ditu. Analisiaren irismena EN15978 [10] arautegian oinarrituko da. Azterketaren emaitzak urteko eta bizitzeko erabilgarria den azalera-unitatearen arabera adieraziko dira. Kasu honetan, eraikinaren erabilera-bizitza (EEB) 50 urtekoa izango da [17]. Sentsibilitate-analisian zehar eraikinaren erabilera-bizitza desberdinak aztertuko dira.

Nahiz eta EN15978 [10] arautegiak BZAren azterketen emaitzak ingurumen-inpaktuaren adierazle desberdinen bidez erakusteko agindu, lan honetan Oinarrizko energia ez-berriztagarrien baliabideen (OEEB) erabilera-adierazlea izango da. Azterketa ekonomikoari dagokionez, erabilitako unitatea «Euroa» izango da.

2. taulan azterketa honetan erabilitako kalkulu-hipotesiak zehazten dira.

2. taula. Azterketa-metodologiaren aldagaiak, informazio-iturriak eta hipotesiak.

\begin{tabular}{c|l}
\hline Bizi-ziklo etapa & \multicolumn{1}{c}{ Hipotesiak } \\
\hline $\begin{array}{c}\text { Ekoizpena } \\
\text { (A1-3) }\end{array}$ & $\begin{array}{l}\text { Ecoinvent [47], GaBi [48] eta Produktuaren Ingurumen Adie- } \\
\text { razpena (PIA) [49, 50, 51, 52] informazio-iturriak erabiliko } \\
\text { dira birgaitze-estrategia bakoitzaren barne-energiaren (BE) in- } \\
\text { paktua zehazteko. Inpaktu ekonomikoa informazio-iturri des- } \\
\text { berdinetan oinarrituko da [53, 54, 55, 56, 57]. }\end{array}$ \\
$\begin{array}{c}\text { Garraioa } \\
\text { (A4) }\end{array}$ & $\begin{array}{l}\text { garraiatzeko agertoki proposatzen dira: 50 km (probintzia } \\
\text { barnekoa), 120 km (eskualde barnekoa) eta 300 km (nazio } \\
\text { barnekoa [58]). Garraiatze-kostua «presto» datu-basearen bi- } \\
\text { dez zehaztu da [59]. }\end{array}$ \\
\hline $\begin{array}{c}\text { Eraikuntza-prozesua } \\
\text { (A5) }\end{array}$ & $\begin{array}{l}\text { Birgaitze-estrategia bakoitza eraikuntza-prozesuan zehar sor- } \\
\text { turiko hondakinen kudeaketa-prozesuan zenbatuko da }\end{array}$ \\
\hline $\begin{array}{c}\text { Mantentzea } \\
\text { (B2) }\end{array}$ & $\begin{array}{l}\text { Etapa honen ingurumen-azterketarik ez da egingo [11]. Az- } \\
\text { terketa ekonomikoan \% 1,5eko inflazio-tasa izango da kon- } \\
\text { tuan [60] }\end{array}$ \\
\hline
\end{tabular}


Bizi-ziklo analisiaren irismenaren optimizazioa eraikinen birgaitze energetikoen ingurumen- eta ekonomia-analisietan

\begin{tabular}{c|l}
\hline Bizi-ziklo etapa & \multicolumn{1}{c}{ Hipotesiak } \\
\hline $\begin{array}{c}\text { Ordezkapena } \\
\text { (B4) }\end{array}$ & $\begin{array}{l}\text { Informazio-iturri desberdinetan oinarrituta [61, 62], birgaitze- } \\
\text { materialen eta sistemen aurreikusitako erabilera-bizitza (AEB) } \\
\text { desberdinak zehaztu dira. }\end{array}$ \\
\hline $\begin{array}{c}\text { Erabilera etapako } \\
\text { energia-kontsumoa } \\
\text { (B6) }\end{array}$ & $\begin{array}{l}\text { Eraikinen Espainiako arautegiak [63] zehazturiko aldagaietan } \\
\text { oinarrituta, Design Builder software-aren bidez eraikinaren } \\
\text { energia-eskaria neurtu da [64]. Beste aldagaiak informazio- } \\
\text { ituri desberdinen bidez zehaztuko dira: } \\
\text { - Ingurumen konbertsioaren faktorea: gas naturala [47] eta } \\
\text { elektrizitatea [65]. } \\
\text { - Energiaren prezioa [66]. } \\
\text { - Energia-prezioaren igoera (EPI) [67]. }\end{array}$ \\
\hline $\begin{array}{c}\text { Deuseztapena } \\
\text { (C1-4) }\end{array}$ & $\begin{array}{l}\text { Birgaitze-estrategia bakoitzaren parte diren produktuen eta } \\
\text { sistemen kudeaketa gunera arteko garraio eta horien deusezta- } \\
\text { tze-prozesuaren inpaktuak zenbatu dira. }\end{array}$ \\
\hline \multicolumn{2}{c}{}
\end{tabular}

\section{AZTERKETA KASUAREN DESKRIBAPENA}

Balidazio honetan zehar lorturiko emaitzak gaur egungo eraikin-multzo gehienetan aplikagarriak izan daitezen, birgaitze potentzial handia duen eraikin mota baten analisian oinarrituko da lan hau: CTE-79 araudia baino lehen inolako isolamendu termikorik gabe [68] 1960-80 urteen artean eraikitako etxebizitza-blokeak. Azpimarratu behar da eraikin mota horrek ondo ordezkatzen duela Euskadiko eraikin-parkearen multzo nagusi bat. Metodologia hau balidatzeko erabilitako eraikina Donostian, Amara auzoan,1963an eraikitako etxebizitza bloke bat izan da (ikus 2. irudia).

Donostiako urteko batez besteko tenperatura $14^{\circ} \mathrm{C}$-koa da. Udako batez besteko tenperatura, aldiz, $20^{\circ} \mathrm{C}-\mathrm{z}$ azpikoa da eta, ondorioz, ez da normalean hozte-sistemarik behar, are gutxiago estalpeak edo itzala ematen duten elementuak eraikinetan erabiliz gero. Neguko batez besteko tenperatura, ordea, $10^{\circ} \mathrm{C}$-koa da gutxi gorabehera; beraz, berogailu-sistemak beharrezkoak dira.

Azterturiko eraikina hirigune batean kokatzen da beste 4 eraikinen artean. Hori dela eta, inguruko eraikinek sorturiko itzala faktore garrantzitsutzat hartu behar da. Eraikinaren orientazioa eta inguruko eraikinen garaiera dela eta, neguko solstizioan, goiko pisuan hego-ekialderantz dauden etxebizitzek bakarrik jasango dute kontuan hartzeko eguzki-irradiazioa. Udan, berriz, iparralderantz dauden bi fatxadek ez dute ia eguzki-izpi zuzenik jasango. 


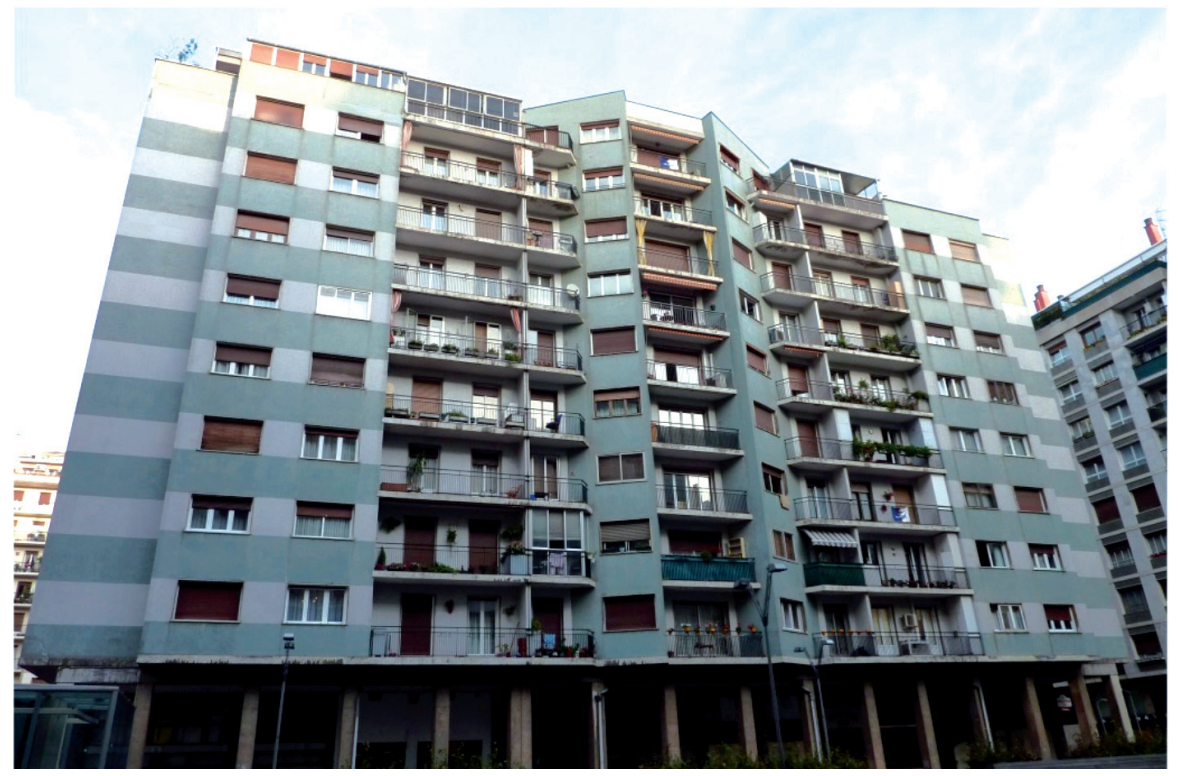

2. irudia. Donostian kokaturiko balidazio-eraikinaren gaur egungo argazkia.

Eraikina behe solairu komertzial batez eta etxebizitza erabilerako 9 solairuz osatuta dago. Berokuntza-sistema 0,92ko errendimendu nominaldun gas naturalezko sistema zentralizatu batean oinarritzen da. Etxebizitzak aireztapen natural bidez aireztatzen dira eta ur beroaren hornikuntza galdara elektriko batean oinarritzen da. Gaur egungo eraikuntza-sistemaren atal nagusien ezaugarri termikoei dagokienez (ikus 3. taula), jatorrizko arkitektura-dokumentuetan oinarrituta, ondorengo balioak zehaztu dira: fatxada $1,12 \mathrm{~W} /\left(\mathrm{m}^{2} \cdot \mathrm{K}\right)$; estalkia $2,34 \mathrm{~W} /\left(\mathrm{m}^{2} \cdot \mathrm{K}\right)$; beirak $5,77 \mathrm{~W} /\left(\mathrm{m}^{2} \cdot \mathrm{K}\right)$; eta markoak 4,2 $\mathrm{W} /\left(\mathrm{m}^{2} \cdot \mathrm{K}\right)$.

Azterketa-metodologiaren aldagaietan oinarrituta, 4. taulak gaur egungo eraikinaren erabilera-etaparen ingurumen- eta ekonomia-inpaktua erakusten du. Balore horietan ikus daitekeen bezala, azterturiko eraikinaren erabilera-etaparen inpaktua oso altua da, birgaitzearen ondoriozko erabilera-etaparen emaitzak oso onak izango direla aurreikusiz. 
3. taula. Gaur egungo eraikinaren azalaren konposizioa eta $U$ baloreak (W/ $\left.\left(\mathrm{m}^{2} \cdot \mathrm{K}\right)\right)[45]$.

\begin{tabular}{|c|c|c|c|c|}
\hline & $\begin{array}{l}\text { Lodiera } \\
(\mathrm{mm})\end{array}$ & $\begin{array}{c}\text { Dentsitatea } \\
\left(\mathrm{kg} / \mathrm{m}^{3}\right)\end{array}$ & $\begin{array}{c}\text { Eroankortasun termikoa } \\
(\mathrm{W} /(\mathrm{m} \cdot \mathrm{k}))\end{array}$ & $\begin{array}{c}U \text { balorea } \\
\left(\mathrm{W} /\left(\mathrm{m}^{2} \cdot \mathrm{K}\right)\right)\end{array}$ \\
\hline \multicolumn{5}{|l|}{ Fatxada } \\
\hline Kanpoko zementua & 10 & 1.350 & 0,70 & \multirow{5}{*}{1,12} \\
\hline Adreilu barne-huts bikoitza & 110 & 930 & 0,37 & \\
\hline Aire-ganbera & 50 & NA & Ez dagokio (ED) & \\
\hline Adreilu barne-huts bikoitza & 110 & 930 & 0,37 & \\
\hline Igeltsu-plaka & 10 & 825 & 0,25 & \\
\hline \multicolumn{5}{|l|}{ Teilatua } \\
\hline Zeramikazko teila & 20 & 2.000 & 1,00 & \multirow{3}{*}{2,34} \\
\hline Aire-ganbera & 50 & ED & $\mathrm{ED}$ & \\
\hline Hormigoi armatua & 200 & 2.400 & 2,30 & \\
\hline \multicolumn{5}{|l|}{ Lehen solairuko forjatua } \\
\hline Hormigoi armatua & 250 & 2.400 & 2,30 & \multirow{3}{*}{1,79} \\
\hline Aire-ganbera & 500 & ED & $\mathrm{ED}$ & \\
\hline Igeltsu-plaka & 15 & 825 & 0,25 & \\
\hline \multicolumn{5}{|l|}{ Leihoak ( $\% 68$ beira eta $\% 32$ markoa) } \\
\hline Beira sinplea (\% 60) & 6 & 2.450 & $* \mathrm{U}$ balorea 5,7 & \multirow{4}{*}{4,71} \\
\hline Beira bikoitza (\% 40) & 10 & 2.450 & *U balorea 2,7 & \\
\hline $\begin{array}{l}\text { Zubi termikoaren hausturarik ga- } \\
\text { beko aluminiozko markoa (\% 60) }\end{array}$ & ED & ED & $* \mathrm{U}$ balorea 5,8 & \\
\hline $\begin{array}{l}\text { Zubi termikoaren hausturadun } \\
\text { aluminiozko markoa }(\% 40)\end{array}$ & $\mathrm{ED}$ & ED & $* \mathrm{U}$ balorea 4,2 & \\
\hline
\end{tabular}

4. taula. Azterketa-kasuaren gaur egungo erabilera-etaparen ingurumen- eta ekonomia-inpaktua.

\begin{tabular}{lcc}
\hline & $\begin{array}{c}\text { Energia-erabilera } \\
\left(\mathrm{MJ} /\left(\mathrm{m}^{2} \cdot \mathrm{a}\right)\right)\end{array}$ & $\begin{array}{c}\text { Energia-kostua } \\
\left(€ /\left(\mathrm{m}^{2} \cdot \mathrm{a}\right)\right)\end{array}$ \\
\hline Berokuntza & 350 & 13,53 \\
Hozkuntza & 0 & 0 \\
Ur beroa & 92 & 10,08 \\
Aireztapena & 0 & 0 \\
Argiztapena & 41 & 4,43 \\
Etxetresnak & 240 & 26,77 \\
\hline
\end{tabular}


5. taula. Azterketa-lanean erabilitako birgaitze-estrategiak.

\begin{tabular}{|c|c|c|c|}
\hline Estrategia & Eraginkortasun-gradua & $\begin{array}{c}\text { Produktuen ingurumenaren } \\
\text { barne-inpaktua }\end{array}$ & $\begin{array}{c}\text { Estrategiaren } \\
\text { akronimoa }\end{array}$ \\
\hline \multirow{3}{*}{$\begin{array}{l}\text { Leihoen ordezkapena } \\
\text { (1) }\end{array}$} & Oinarrizkoa (b) & & $1 b$ \\
\hline & Eraginkorra (e) & & $1 \mathrm{e}$ \\
\hline & Aurreratua (a) & & $1 \mathrm{a}$ \\
\hline \multirow{6}{*}{$\begin{array}{l}\text { Fatxada aireztatua } \\
\qquad(2)\end{array}$} & \multirow{2}{*}{ Oinarrizkoa } & Baxua (1) & $2 \mathrm{bl}$ \\
\hline & & Altua (h) & $2 \mathrm{bh}$ \\
\hline & \multirow{2}{*}{ Eraginkorra } & Baxua & 2el \\
\hline & & Altua & 2eh \\
\hline & \multirow{2}{*}{ Aurreratua } & Baxua & $2 \mathrm{al}$ \\
\hline & & Altua & $2 \mathrm{ah}$ \\
\hline \multirow{6}{*}{$\begin{array}{l}\text { SATE sistema } \\
\text { (3) }\end{array}$} & \multirow{2}{*}{ Oinarrizkoa } & Baxua & $3 \mathrm{bl}$ \\
\hline & & Altua & $3 b h$ \\
\hline & \multirow{2}{*}{ Eraginkorra } & Baxua & 3el \\
\hline & & Altua & $3 \mathrm{eh}$ \\
\hline & \multirow{2}{*}{ Aurreratua } & Baxua & 3al \\
\hline & & Altua & $3 a h$ \\
\hline \multirow{6}{*}{$\begin{array}{l}\text { Barrukoa } \\
\text { (4) }\end{array}$} & \multirow{2}{*}{ Oinarrizkoa } & Baxua & $4 \mathrm{bl}$ \\
\hline & & Altua & $4 \mathrm{bh}$ \\
\hline & \multirow{2}{*}{ Eraginkorra } & Baxua & $4 \mathrm{el}$ \\
\hline & & Altua & $4 \mathrm{eh}$ \\
\hline & \multirow{2}{*}{ Aurreratua } & Baxua & 4al \\
\hline & & Altua & $4 \mathrm{ah}$ \\
\hline \multirow{5}{*}{$\begin{array}{l}\text { Aire-ganbera } \\
\quad(5)\end{array}$} & \multirow{2}{*}{ Oinarrizkoa } & Baxua & $5 \mathrm{bl}$ \\
\hline & & Altua & $5 b h$ \\
\hline & \multirow{2}{*}{ Eraginkorra } & Baxua & $5 \mathrm{el}$ \\
\hline & & Altua & $5 \mathrm{eh}$ \\
\hline & Aurreratua & \multicolumn{2}{|c|}{$\begin{array}{l}\text { Aire-ganberaren neurrien ondorioz, } \\
\text { ezin da aplikatu }\end{array}$} \\
\hline \multirow{3}{*}{$\begin{array}{l}\text { Eguzki-energia termikoa } \\
(6)\end{array}$} & Oinarrizkoa & - & $6 b$ \\
\hline & Eraginkorra & - & $6 e$ \\
\hline & Aurreratua & - & $6 a$ \\
\hline \multirow{2}{*}{$\begin{array}{l}\text { Eguzki-energia fotovoltaikoa } \\
\text { (7) }\end{array}$} & Eraginkorra & - & $7 \mathrm{e}$ \\
\hline & Aurreratua & - & $7 \mathrm{a}$ \\
\hline
\end{tabular}


Bizi-ziklo analisiaren irismenaren optimizazioa eraikinen birgaitze

energetikoen ingurumen- eta ekonomia-analisietan

\subsection{Energiaren birgaitze-estrategien aukeraketa}

Atal honen helburu nagusietako bat etxebizitzak energetikoki birgaitzeko gaur egun merkatuak eskaintzen dituen estrategia ohikoenak kontuan hartu eta definitzea izango da. Horretarako, 8 estrategia-multzo zehaztu dira (ikus 5. taula): gaur egungo leihoen ordezkapena (1), fatxada aireztatuen sistema (2), SATE bezala ezagutzen den kanpoko isolamendu-sistema (3), eraikinaren barrualdeko ezaugarri termikoak hobetzea (4), isolamendua fatxadako aire-ganberan injektatzea (5), eguzki-energia termikoaren sistema (6) eta eguzki-energia fotovoltaikoaren sistema (7). Kalkuluen ikuspuntutik, fatxada aireztatuen eta SATE sistemaren arteko desberdintasun nagusia sistema horien aurreikusitako erabilera-bizitzaren (AEB) eta ekoizpen-etaparen inpaktuen baloreetan oinarritzen da. Aldi berean, fatxada aireztatuaren aire-ganberak eragin zuzena izango du Design Builder [64] software-aren bidez egindako energia-simulazioetan.

Estrategia horiek eraginkortasun-gradu desberdinetan aplikatuko dira: oinarrizkoa, eraginkorra eta aurreratua. Oinarrizko mailako estrategiak gaur egungo arautegiak zehazten dituen gutxieneko betebeharrak bermatzeko modukoak izango dira. Maila eraginkorrean, oinarrizko ezaugarriak $\%$ 30ean hobetuko dira, bai ezaugarri termikoetan, bai energia berriztagarrien erabileran. Maila aurreratuko estrategiak, azkenik, hobekuntza handiak dakartzatenak dira. Birgaitze-estrategiak zehazteko garaian erabiliko den azken aldagaia material mota izango da, bizi-ziklo analisian eragin zuzena izango baitu material bakoitzaren ingurumenaren barne-inpaktuak. Horretarako, estrategiak barne-inpaktu altu eta baxuko materialen erabileraren arabera sailkatuko dira.

\section{AZTERTURIKO BIRGAITZE ESTRATEGIEN BIZI-ZIKLO OSOAREN ANALISIA}

Ondoren aurkeztuko den grafikoaren bidez (3. irudia), azterketa-kasua birgaitzean, bizi-zikloaren etapa bakoitzak izango duen ingurumen- eta ekonomia-inpaktua aztertzen dira. Birgaitutako eraikinaren erabilera-etapan zehar murriztutako inpaktua balore positibo bezala adieraziko da. Bizi-zikloko beste etapa guztien inpaktua, aldiz, balore negatibo bezala adieraziko da.

Ingurumen-analisiari dagokionez, baldintza klimatikoen edo eraikuntza-ezaugarrien ondorioz, beste bizi-zikloko etapetan sorturiko inpaktuarekin alderatuta, birgaitze-estrategia guztietan erabilera-etapan zehar murrizturiko OEEB kopurua askoz handiagoa dela ikus daiteke. Adibidez, muturreko egoerak aztertuz gero, inpaktu positiboaren eta negatiboaren arteko ezberdintasun txikiena «1b» (leiho bikoitza), «2ah» (fatxada aireztatua) eta «7» (eguzki-energia fotovoltaikoa) birgaitze-estrategietan aurkitzen dira, 6-1, 12-1 eta 6-1 erlazioak hurrenez hurren. Barne-energia baxua 
$\triangle \mathrm{A} 1-3 \square \mathrm{A} 4 \square \mathrm{A} 5 \square \mathrm{B} 2 \square \mathrm{B} 4 \_\mathrm{A} 1-3 \square \mathrm{B} 4 \_\mathrm{A} 4 \square \mathrm{B} 4 \_\mathrm{A} 5 \square \mathrm{B} 6 \square \mathrm{C} 1-4$

OEEB erabileraren murrizketa $\left(\mathrm{MJ} /\left(\mathrm{m}^{2} \cdot \mathbf{a}\right)\right)$

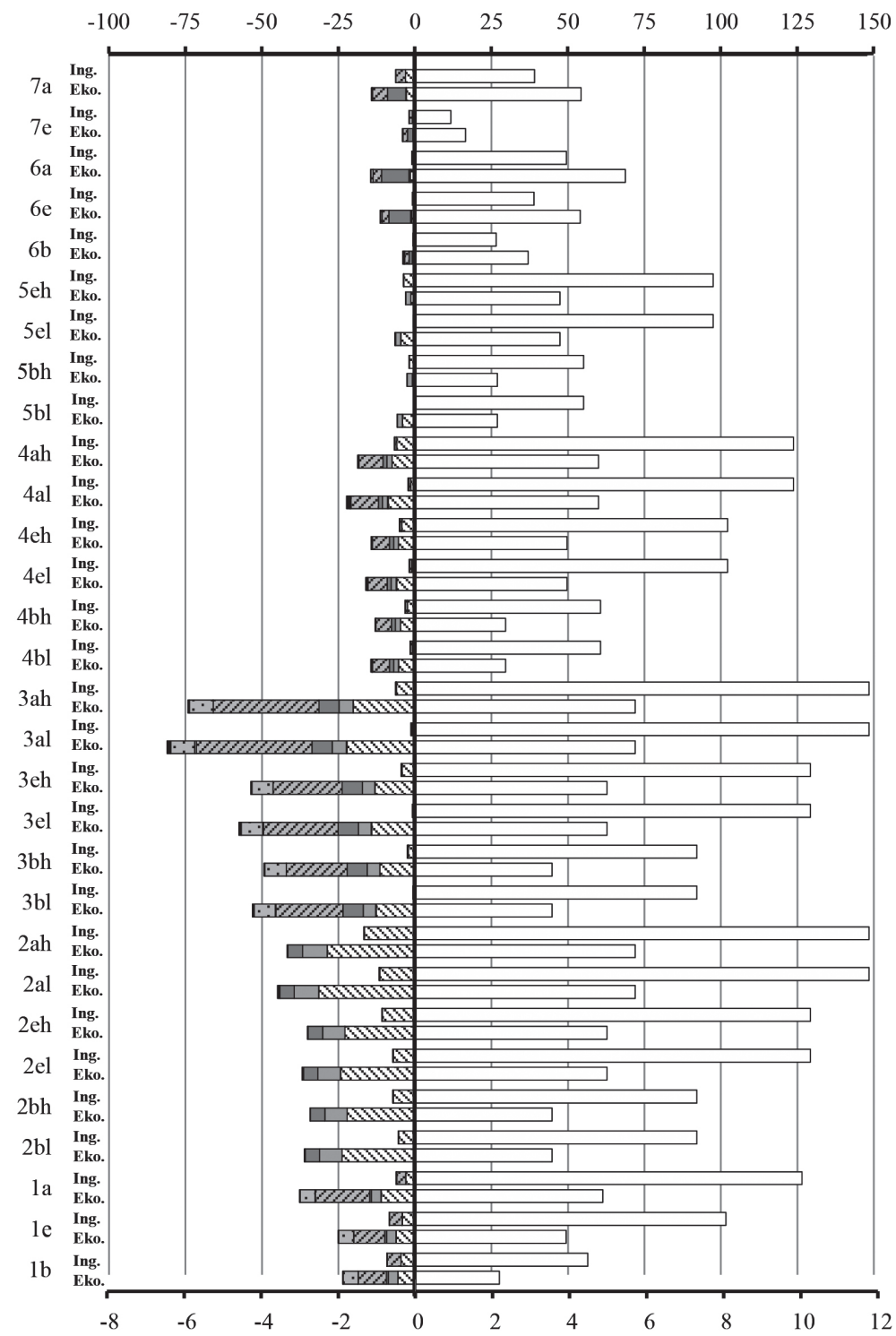

Ekonomia inpaktuaren murrizketa $\left(€ /\left(\mathbf{m}^{2} \cdot \mathbf{a}\right)\right)$

3. irudia. Oinarriarekiko birgaitze-estrategia bakoitzaren OEEB erabileraren $\left(\mathrm{MJ} /\left(\mathrm{m}^{2} \cdot \mathrm{a}\right)\right)$ eta ekonomia-inpaktuaren $\left(€ /\left(\mathrm{m}^{2} \cdot \mathrm{a}\right)\right)$ murrizketa. Laburdurak: «Ing.» ingurumen azterketa eta «Eko.» ekonomia azterketa. 
edo aurreikusitako erabilera-bizitza handia duten materialetan oinarritzen diren birgaitze-estrategietan, aldiz, erlazio hori asko handitzen da, «5bl» eta «5el» (isolamendua fatxadako aire-ganberan injektatzea) birgaitze-estrategietan 200-1 arteko erlazioa izatera iritsirik.

Analisi ekonomikoari dagokionez, ingurumen-emaitzekin alderatuta, bizi-zikloko zenbait etapak oso eragin handia izango dutela ikus daiteke. Ondorioz, aurreztuko den energia kopuruaren inpaktua baino beste etapen eragina handiagoa izango da. Nabarmentzekoak dira «3» (SATE sistema) birgaitze-estrategiaren multzoko emaitzak, beraien bizi-ziklo osoko analisi ekonomikoaren balantzea negatiboa baita.

\section{BIZI-ZIKLOKO ETAPA DESBERDINEN ANALISIA}

Atal honek bizi-zikloko etapa bakoitzak birgaituriko eraikinak bere bizi-ziklo osoan zehar murriztuko duen inpaktu osoarekiko duen erlazioa edo ehuneko balorea lantzen du (ikus 6. taulako adibidea).

6. taula. Bizi-zikloko etapa bakoitzaren emaitzen adibidea (MJ eta $€$-tan) eta aukeratutako estrategiaren ( «2ah») ehuneko balioa.

\begin{tabular}{|c|c|c|c|c|c|}
\hline \multirow{2}{*}{\multicolumn{2}{|c|}{ Bizi-zikloko etapa }} & \multicolumn{2}{|c|}{ Ingurumena } & \multicolumn{2}{|c|}{ Ekonomikoa } \\
\hline & & $\left(\mathrm{MJ} /\left(\mathrm{m}^{2} \cdot \mathrm{a}\right)\right)$ & $\%$ & $\left(€ /\left(\mathrm{m}^{2} \cdot \mathrm{a}\right)\right)$ & $\%$ \\
\hline Ekoizpena & A1-3 & 16 & 10,035 & 2,3 & 25,48 \\
\hline Garraioa & A4 & 0,024 & 0,014 & 0,0046 & 0,05 \\
\hline Eraikuntza-prozesua & A5 & 0,0021 & 0,001 & 0,64 & 7,04 \\
\hline Mantentzea & B2 & - & - & 0,38 & 4,15 \\
\hline Ordezkapena & B4 & 0 & 0 & 0 & 0 \\
\hline $\begin{array}{l}\text { Erabilera etapako energia-kon- } \\
\text { tsumoa (eraikin birgaitua) }\end{array}$ & B6 & 148 & 89,908 & 5,7 & 63,00 \\
\hline Deuseztapena & C1-4 & 0,068 & 0,041 & 0,024 & 0,27 \\
\hline Guztira & Bizi-zikloa & 165 & 100 & 9,03 & 100 \\
\hline
\end{tabular}

Ingurumen-azterketari dagokionez (ikus 4. irudia), lorturiko emaitzek zenbait ondorio garbi zehazten dituzte:

- Garraioa (A4), eraikuntza-prozesu (A5) eta deuseztapen (C1-4) etapen eragina \% 0,1 baino txikiagoa izango da azterturiko birgaitzeestrategia guztietan. 
- Ekoizpen-etapari dagokionez (A1-3), emaitzak \% 0,3tik \% 10eraino alda daitezke. Ondorioz, lehen fasean ez da komeni etapa hau ebaluazio sistematik ateratzea.

- Beste zenbait lanen emaitzak berretsiz [45, 69, 70], birgaitze-estrategia guztietan erabilera-etapan (B6) murrizturiko ingurumen-inpaktuak duen eragina da garrantzitsuena, \% 86tik ia \% 100 balioa lortuz.

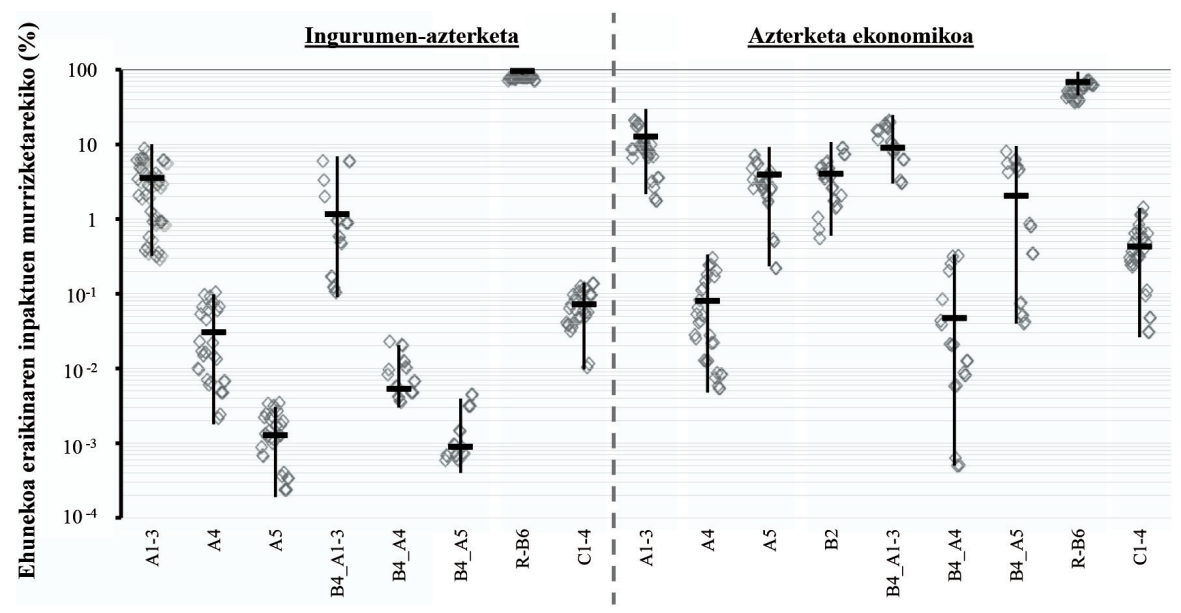

4. irudia. Bizi-zikloko etapa bakoitzaren inpaktuaren ehunekoa birgaitutako eraikinaren inpaktuen murrizketa orokorrarekiko.

Azterketa ekonomikoari dagokionez (ikus 4. irudia):

- Kasu bakar batean izan ezik, garraio (A4) eta deuseztapen (C1-4) etapen eragina \% 1 baino txikiagoa izango da azterturiko birgaitzeestrategia guztietan.

- Ekoizpen-etaparen (A1-3) eragina \% 30 izatera irits daiteke.

- Eraikuntza-prozesuaren (A5) inpaktua ere asko handitzen da, \% 9 inguruko balioak lortuz.

- Mantentze-etapa (B2) ere \% 10 inguruko balioetara iristen da.

- Azkenik, erabilera-etapan (B6) murrizturiko inpaktuari dagokionez, emaitzek adierazten dute bere ehuneko balorea \% 45en eta \% 93ren artean aurkitzen dela.

\section{SENTSIBILITATE ANALISIA}

Hasiera batean, emaitza horietan oinarrituta, ebaluazio-sistemaren irismenaren optimizazioa proposatzeko aukera egongo litzateke. Hala ere, kalkulu horien emaitzetan eta ondorioen irakurketan eragin zuzena duten hainbat alda- 
gai aurkitzen dira (ikus 7. taula): eraikinaren erabilera-bizitza (EEB), material bakoitzaren aurreikusitako erabilera-bizitza (AEB), materialen garraiatze-distantzia (D), baldintza klimatikoak (BK), barne-energiaren kalkulu-metodologiak (BE), erabilera-etapan zeharreko aldaketak (EEA), konbertsio-faktoreak $(\mathrm{KF})$, energiaren prezioaren bilakaeraren $(\mathrm{EPB})$ joerak edo inflazio-tasaren (IT) aldaketa, besteak beste. Ondorioz, etxebizitzen birgaitze energetikoaren ebaluazio-sistemaren irismen optimizatu orokor bat lortzeko asmoz, aldagai berri horiek sortuko dituzten egoera desberdin guztiak definitu eta egoera bakoitzean birgaitze-estrategia guztiak berriz aztertuko dira, estrategia bakoitzak bizi-zikloko etapa bakoitzean izango duen ingurumen- eta ekonomia-inpaktua zenbatu eta ehuneko balorea zehaztuz. Kasu honetan, bizi-ziklo bakoitzeko 775 ingurumen eta 682 ekonomia analisi egingo direlarik.

7. taula. Hasierako hipotesiak (0 egoera) eta aldaketak (egoera berriak) sentsibilitate-analisirako.

\begin{tabular}{lccccc}
\hline & Unitatea & 0. egoera & 1. egoera & 2. egoera & 3. egoera \\
\hline $\mathrm{EEB}_{\mathrm{b}}$ & Urtea & 50 & 100 & 25 & - \\
$\mathrm{AEB}_{\mathrm{m}}$ & Urtea & {$[61,62]$} & Erdia & 50 & - \\
$\mathrm{D}_{\mathrm{m}}$ & $\mathrm{km}$ & Azterketa kasua & 50 & 300 & 1.000 \\
$\mathrm{BK}$ & - & Donostia & Palermo & Oslo & - \\
$\mathrm{BE}$ & - & Prozesu & Hibridoa $[37,71]$ & & - \\
$\mathrm{EEA}$ & - & Azterketa kasua & $\%-20[72,73]$ & $\%+20[72,73]$ & - \\
$\mathrm{KF}_{\text {elektrizitatea }}$ & $\mathrm{MJ} / \mathrm{MJ}$ & 1,74 & $\%-20$ & $\%+20$ & - \\
$\mathrm{EPB}_{\text {elektrizitatea }}$ & $\%$ & 4 & 0 & 8 & - \\
$\mathrm{EPB}_{\text {gas naturala }}$ & $\%$ & 3 & 0 & 6 & - \\
$\mathrm{IT}$ & $\%$ & 1,5 & 0 & 3 & - \\
\hline
\end{tabular}

Azkenik, egoera potentzial berriak aztertzeko, 7. taulan definituriko aldagai desberdinen arteko konbinazioaren ondorioz, 8 birgaitze-agertoki berri garatu dira (ikus 8. taula).

8. taula. Birgaitze-konbinazio (K) berriak.

\begin{tabular}{lcccccccc}
\hline & $\mathrm{K}_{1}$ & $\mathrm{~K}_{2}$ & $\mathrm{~K}_{3}$ & $\mathrm{~K}_{4}$ & $\mathrm{~K}_{5}$ & $\mathrm{~K}_{6}$ & $\mathrm{~K}_{7}$ & $\mathrm{~K}_{8}$ \\
\hline $\mathrm{EEB}_{\mathrm{b}}$ & 100 & 100 & 25 & 25 & 100 & 100 & 25 & 25 \\
$\mathrm{AEB}_{\mathrm{m}}$ & Erdia & Erdia & 50 & 50 & Erdia & Erdia & 50 & 50 \\
$\mathrm{BK}$ & Palermo & Palermo & Palermo & Palermo & Oslo & Oslo & Oslo & Oslo \\
$\mathrm{BE}_{\mathrm{m}}$ & Hibridoa $(\mathrm{H})$ & Prozesua $(\mathrm{P})$ & $\mathrm{H}$ & $\mathrm{P}$ & $\mathrm{H}$ & $\mathrm{P}$ & $\mathrm{H}$ & $\mathrm{P}$ \\
$\mathrm{EEA}$ & $\%-20$ & $\%-20$ & $\%-20$ & $\%-20$ & $\%+20$ & $\%+20$ & $\%+20$ & $\%+20$ \\
$\mathrm{KF}_{\text {elektrizitatea }}$ & $\%-20$ & $\%-20$ & $\%-20$ & $\%-20$ & $\%+20$ & $\%+20$ & $\%+20$ & $\%+20$ \\
EPB $_{\text {elektrizitatea }}$ & $\% 0$ & $\% 0$ & $\% 0$ & $\% 0$ & $\% 8$ & $\% 8$ & $\% 8$ & $\% 8$ \\
EPB $_{\text {gas naturala }}$ & $\% 0$ & $\% 0$ & $\% 0$ & $\% 0$ & $\% 6$ & $\% 6$ & $\% 6$ & $\% 6$ \\
$\mathrm{IT}$ & $\% 0$ & $\% 0$ & $\% 0$ & $\% 0$ & $\% 3$ & $\% 3$ & $\% 3$ & $\% 3$ \\
\hline
\end{tabular}




\subsection{Sentsibilitate-analisiaren emaitzak}

Aurreko ataletan azaldu den metodologian oinarriturik, ondorengo 5. irudiak 775 ingurumen eta 682 ekonomia egoeren emaitzak erakusten ditu.

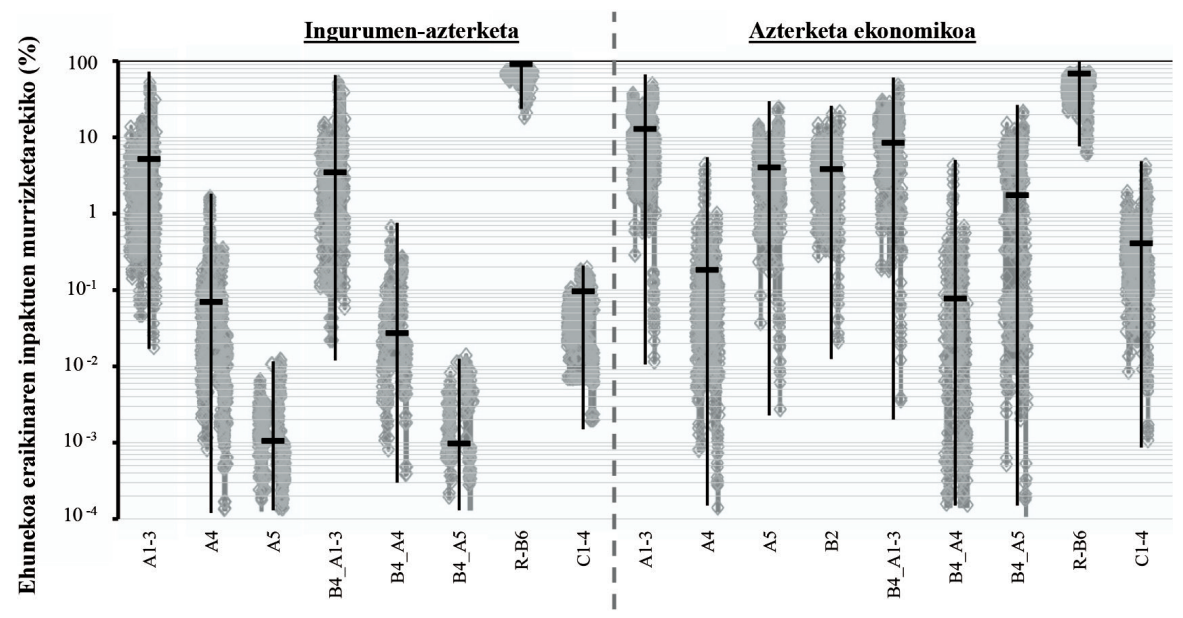

5. irudia. Bizi-zikloko etapa bakoitzarekiko inpaktu globalaren ehunekoa sentsibilitate-analisitik sortutako egoera guztientzat.

Sailkatze honetan oinarriturik, emaitzen lehen irakurketak erakusten du aztertutako 775 egoeretatik 765 ingurumen-azterketetan, garraio (A4), eraikuntza-prozesu (A5) eta deuseztapen (C1-4) etapen inpaktu-murrizketa orokorrarekiko balioa \% 1 baino txikiagoa dela. Analisi ekonomikoari dagokionez, 682 egoeretatik 660 ekonomia-azterketetan, garraio (A4) eta deuseztapen (C1-4) etapen inpaktu-murrizketa orokorrarekiko balioak ere $\% 1$ baino txikiagoak dira, eta kasu guztietan \% 5 baino txikiagoak. Bizi-zikloko beste etapei dagokienez, azterlan honetan bi birgaitze talde edo agertoki erabat desberdin finkatu dira. Batetik, arrazoi desberdinen ondorioz (eraikinaren kokapena edo erabilera-bizitza adibidez) birgaitze-estrategiak aplikatu ondoren, eraikinaren erabilera-etaparen inpaktuaren murrizketa bizi-zikloan zehar txikia den egoerak aurkitzen dira. Kasu horietan, erabilera-etapan (B6) zehar murrizturiko inpaktua zenbatzeaz gain, beharrezkoa izango da bizi-zikloaren beste etapetan sortutako inpaktuak ebaluatzea. Bestalde, birgaitze-estrategiak aplikatu ondoren, eraikinaren erabilera-etaparen inpaktuaren murrizketa handia den egoeretan, guztiz bestelako emaitza islatzen da. 573 ingurumen eta 126 ekonomi egoeretan, bizi-ziklo osoan zehar murrizturiko inpaktuarekiko erabilera-etaparen (B6) ehuneko balorea \% 90 baino handiagoa izango da. Ondorioz, bizi-zikloko beste 
etapa guztiek birgaitzearen ingurumen- eta ekonomia-analisian \% 10eko eragin zuzena baino txikiagoa izango dute.

\section{ONDORIOAK}

Artikulu honek etxebizitza-blokeen birgaitze energetikoko proiektuetan bizi-zikloaren etapa bakoitzaren eta birgaituriko eraikinak bere bizi-ziklo osoan zehar erdietsiriko inpaktu-murrizketa orokorraren arteko erlazioa landu du. Lanean zehar lorturiko emaitzen ondorioz ikus daiteke nola oso zaila den bizi-zikloko metodologiaren bidez lorturiko emaitzen zehaztasunaren eta metodologia horren erabileraren zailtasunaren arteko harremana definituko duen emaitza bakar bat lortzea. Hau da, eraikinen birgaitze energetikoen ingurumen- eta ekonomia-analisietan bizi-ziklo analisiaren irismen optimo bakar bat zehaztea ezinezkoa da, kasu bakoitzean hainbat aldagaik eragin zuzena baitute sinplifikazio horretan.

Ugariak dira erabakiak hartzeko prozesuan bizi-zikloaren zenbait etapa kontuan hartzeko beharra islatzen duten emaitzak. Esate baterako, klima epeletan kokatuta dauden eraikinetan, metodologia hau ezarri eta erabilera-etapaz gain, bizi-zikloko beste zenbait etapa ere aztertzeko beharra azpimarratu da. Bestalde, eskualde klimatiko hotzetan edo eraikinaren erabilera-etapan zehar inpaktuaren murrizketa handia duten eskualdeetan kokatutako eraikinetako emaitzek frogatzen dute metodologia konplexu hau aplikatzeak ez diela zehaztasun handiagorik ematen azken emaitzei. Hau da, birgaitze-estrategia bat aztertzerakoan, egoera horietan eraikinaren erabilera-etapa bakarrik aztertuta nahikoa izango litzateke, bizi-zikloko beste etapen inpaktu zuzena eraikinaren inpaktu osoarekiko oso txikia baita.

Horregatik guztiarengatik, beharrezkoa izango da birgaitze-estrategien inpaktuak aztertzerakoan, estrategia jakin bat lehenesteko garaian, birgaitze-politikak zehazterakoan edo energia-portaeraren ziurtagiri berrien irismena definitzerakoan, baldintza klimatiko eta eraikin-parkearen prestazio termikoen arabera herrialde edo gune geografiko bakoitzean bizi-ziklo metodologian oinarritzen den ebaluazio-sistemaren irismen optimizatu bat zehaztea.

\section{ESKER ONAK}

Artikulu hau Eusko Jaurlaritzaren laguntzarekin garatu da, Hezkuntza, Hizkuntza Politika eta Kultura Sailaren Doktore Aurreko Programaren bidez (BFI-2011-92). 


\section{BIBLIOGRAFIA}

[1] IEA (2013). International Energy Agency (IEA). $\mathrm{CO}_{2}$ emissions from fuel combustion Highlights; Paris, France, 2013; pp. 600.

[2] Power, A. (2008). Does demolition or refurbishment of old and inefficient homes help to increase our environmental, social and economic viability? Energy Policy, 36 (12), 4487-4501.

[3] CEC (2014a). European Commission. Resource efficiency opportunities in the building sector. COM (2014) 445 final. Brussels, 1.7.2014.

[4] CEC (2014b). European Commission. Energy Efficiency and its contribution to energy security and the 2030 Framework for climate and energy policy. COM (2014) 520 final. Brussels, 23.7.2014.

[5] Hernandez, P., Kenny, P. (2010). From net energy to zero energy buildings: Defining life cycle zero energy buildings (LC-ZEB). Energy Build., 42, 815821.

[6] ISO, International Standardization Organization (1997). Environmental management - Life cycle assessment - Principles and framework. ISO 14040:1997.

[7] ISO, International Standardization Organization (1998). Environmental management - Life cycle assessment - Requirements and guidelines. ISO 14044:2006.

[8] CEN TC 350. European Committee for Standardization, Technical Committees. Sustainability of construction works.

[9] ISO, International Standardization Organization. Sustainability in buildings and civil engineering works. ISO TC 59/SC17.

[10] EN 15978 (2011). Sustainability of construction works - Assessment of environmental performance of buildings - Calculation method. 2011.

[11] Zabalza, I., Aranda, A., Scarpellini, S. (2009). Life cycle assessment in buildings: State-of-the-art and simplified LCA methodology as a complement for building certification. Build. Environ., 44, 2510-2520.

[12] Blom, I., Itard, L., Meijer, A. (2010). Environmental impact of dwellings in use: Maintenance of façade components.Build. Environ., 45, 2526-2538.

[13] Blengini, G.A. (2009). Life cycle of buildings, demolition and recycling potential: a case study in Turin-Italy. Build. Environ., 44:319-30.

[14] Gustavsson, L., Joelsson, A. (2010). Life cycle primary energy analysis of residential buildings. Energy Build., 42, 210-220.

[15] Ortiz, O., Castells, F., Sonnemann, G. (2010). Life cycle assessment of two dwellings: One in Spain, a developed country, and one in Colombia, a country under development. Sci. Total Environ., 408, 2435-2443.

[16] Dodoo, A., Gustavsson, L., Sathre, R. (2010). Life cycle primary energy implication of retrofitting a wood-framed apartment building to passive house standard. Resour. Conserv. Recycl., 54, 1152-1160.

[17] Malmqvist, T., Galumann, M., Scarpellini, S., Zabalza, I., Aranada, A., Llera, E., Diaz, S. (2011). Life cycle assessment in buildings: The ENSLIC simplified method and guidelines. Energy, 36, 1900-1907. 
[18] Tae, S., Shin, S., Kim, H., Ha, S., Lee, J., Han, S. (2011). Life cycle environmental loads and economic efficiencies of apartment buildings built with plaster board drywall. Renew Sustain Energy Rev, 15:4145-55.

[19] Wallhagen, M., Glaumann, M., Malmqvist, T. (2011). Basic building life cycle calculations to decrease contribution to climate change - case study on an office building in Sweden. Build. Environ., 46:1863-71.

[20] Rossi, B., Marique, A.-F., Glaumann, M., Reiter, S. (2012). Life-cycle assessment of residential buildings in three different European locations, basic tool. Build. Environ., 51:395-401.

[21] Sharma, A., Shree, V., Nautiyal, H. (2012). Life cycle environmental assessment of an educational building in Northern India: A case study. Sustainable Cities and Society, 4:22-8.

[22] Gazulla, C., Oregi, X. (2012). EeBGuide Background Report for Buildings. LCA of the building Amara (Donostia, Spain).

[23] Iyer, U., Wong, J.P.C. (2012). Evaluation of whole life cycle assessment for heritage buildings in Australia. Build. Environ., 47:138-49.

[24] Stephan, A., Crawford, R.H., Myttenaere, K. (2012). Towards a comprehensive life cycle energy analysis framework for residential buildings. Energy Build., 55, 592-600.

[25] Cuéllar, R.M., Azapagic, A. (2012). Environmental impacts of the UK residential sector: life cycle assessment of houses. Build. Environ., 54:86-99.

[26] Ramesh, T., Prakash, R., Shukla, K.K. (2012). Life cycle energy analysis of a residential building with different envelopes and climates in Indian context. Appl. Energy, 89, 193-202.

[27] Stephan, A., Crawford, R.H., Myttenaere, K. (2013) A comprehensive assessment of the life cycle energy demand of passive houses. Appl. Energy, 112, 23-34.

[28] Asdrubali, F., Baldassarri, C., Fthenakis, V. (2013). Life cycle analysis in the construction sector: guiding the optimization of conventional Italian buildings. Energy Build.; 64:73-89.

[29] Allacker, K., De Troyer, F. (2013). Moving towards a more sustainable Belgian dwelling stock: the passive standard as the next step? Journal of Green Building, 8(2): 112-132.

[30] Paulsen, J.S., Sposto, R.M. (2013). A life cycle energy analysis of social housing in Brazil: case study for the program «MY HOUSE MY LIFE». Energy Build., 57:95-102.

[31] Vrijders, J., Wastiels, L. (2013). Nearly Zero Energy Renovation of houses: Life cycle costs and environmental impact. International Sustainable Building Conference, Graz. 87-94.

[32] De Angelis, E., Dotelli, G., Pittau, F., La Torre, A., Porcino, C., Pansa, G., Villa, N. (2013). LCA and LCC based Energy Optimization of Building Renovation Strategies. International Sustainable Building Conference, Graz. 77-86.

[33] Ostermeyer, Y., Wallbaum, H., Reuter, F. (2013). Multidimensional Pareto optimization as an approach for site-specific building refurbishment solu- 
tions applicable for life cycle sustainability assessment. International Journal of Life Cycle Assessment, 18(9): 1762-1779.

[34] Mosteiro, M., Krogmann, U., Wallbaum, H., Ostermeyer, Y., Senick, J.S., Andrews, C.J. (2014). Relative importance of electricity sources and construction practices in residential buildings: A Swiss-US comparison of energy related life-cycle impacts. Energy Build., 68, 620-631.

[35] Bull, J., Gupta, A., Mumovic, D., Kimpian, J. (2014). Life cycle cost and carbon footprint of energy efficient refurbishments to 20th century UK school buildings. Int J Sustain Build. Environ., 3:1-17.

[36] Dodoo, A., Gustavsson, L., Sathre, R. (2014). Lifecycle primary energy analysis of low-energy timber building systems for multi-storey residential buildings. Energy Build., 81, 84-97.

[37] Stephan, A., Stephan, L. (2014). Reducing the total life cycle energy demand of recent residential buildings in Lebanon. Energy; 74:618-37.

[38] Russell-Smith, S.V., Lepech, M.D., Fruchter, R., Meyer, Y.B. (2014). Sustainable target value design: integrating life cycle assessment and target value design to improve building energy and environmental performance. J Clean Prod., 88, 43-51.

[39] Rodriguez, C., Freire, F. (2014). Integrated life-cycle assessment and thermal dynamic simulation of alternative scenarios for the roof retrofit of a house. Build. Environ., 81:204-15.

[40] Bastos, J., Batterman, S.A., Freire, F. (2014). Life-cycle energy and greenhouse gas analysis of three building types in a residential area in Lisbon. Energy Build, 69:344-53.

[41] Devi, L.P., Palaniappan, S. (2014). A case study on life cycle energy use of residential building in Southern India. Energy Build., 80:247-59.

[42] Cellura, M., Guarino, F., Longo, S., Mistretta, M. (2014). Energy life-cycle approach in Net zero energy buildings balance: operation and embodied energy of an Italian case study. Energy Build., 72:371-381.

[43] Assiego de Larriva, R., Calleja, G., Cejudo, J.M., Raugei, M., Fullana, P. (2014). A decision-making LCA for energy refurbishment of buildings: conditions of comfort. Energy Build., 70:333-42.

[44] Cetiner, I., Edis, E. (2014). An environmental and economic sustainability assessment method for the retrofitting of residential buildings. Energy Build., 74: $132-140$.

[45] Oregi, X., Hernandez, P., Gazulla, C., Isasa, M. (2015). Integrating Simplified and Full Life Cycle Approaches in Decision Making for Building Energy Refurbishment: Benefits and Barriers. Buildings, 5(2), 354-380.

[46] EN 16627:2015 (2015). Sustainability of Construction Works - Assessment economic performance of buildings - Calculation methods.

[47] Ecoinvent Centre (2014). Swiss Centre for Life Cycle Inventories. Düberdorf, Suiza.

[48] GaBi (2014). Product sustainability performance solutions by PE Europe $\mathrm{GmbH}$ and IKP University of Stuttgart. 
[49] Saint-Gobain Glass, Declaration Environnementale et Sanitarie. SGG CLIMAPLUS. AFNOR Registrierungsnummer N. ${ }^{\circ}$ 08-257:2011.

[50] Saint-Gobain Glass, Declaration Environnementale et Sanitarie SGG CLIMATOP AFNOR: 08-259:2011.

[51] Institut Bauen und Umwelt (IBU) e.V. FPX - Fachvereinigung PolystyrolExtruderschaumstoff, 2014. EPD-FPX-20140156-IBE1-DE.

[52] Institut Bauen und Umwelt (IBU) e.V. GUTEX Holzfaserplattenwerk H, 2015. Henselmann GmbH + Co KG. EPD-GTX-20140222-IBC2-DE.

[53] Verband der Fenster- und Fassadenhersteller e.V. \& Bundesverband Flachglas e.V.: In neuem Licht. Energetische Modernisierung von alten Fenstern. VFF \& BF, Frankfurt a.M./Troisdorf, 2014.

[54] Economic of deep renovation; Implications of a Set of Case Studies, 2010. ECOFYS and EURIMA, 2010 Available online: http://www.eurima.org/ uploads/ModuleXtender/Publications/51/Economics_of_Deep_Renovation_ Ecofys_IX_Study_Design_FINAL_01_02_2011_Web_VERSION.pdf (2017ko otsaila).

[55] Generador de Precios, España. CYPE Ingenieros. Available online: http:// www.generadordeprecios.info/ (2017ko otsaila).

[56] Solar district heating guidelines, 2012. Available online: http://solar-districtheating.eu/Portals/0/Factsheets/SDH-WP3-D31-D32_August2012.pdf (2017ko otsaila).

[57] Smestad, G.P. The Basic Economics of Photovoltaics, 2008. Solar Energy Materials and Solar Cells, P.O. Box 5729, San José, California 95150-5729, U.S.A.

[58] Lasvaux, S. (2010). Study of a simplified model for the Life Cycle Assessment of buildings, $\mathrm{PhD}$ thesis, MINES ParisTech.

[59] Economic data base Presto. Available online at: http://www.acae.es/ (2017ko otsaila).

[60] Global Rates. Available online: http://es.global-rates.com/estadisticas-economicas/inflacion/indice-de-precios-al-consumo/ipca/ipca.aspx (2017ko otsaila).

[61] National association of Home Builders (NAHB) \& and Bank of America. Study of Life Expectancy of Home Materials, edited by J. Jackson, 1-15. Washington, 2007.

[62] Fthenakis, V., Kim, H.C., Held, M., Raugei, M., Krones, J. (2009). Update of PV energy payback times and life-cycle greenhouse gas emissions, in 24th European Photovoltaic Solar Energy Conference and Exhibition. Hamburg, Germany.

[63] Spanish Technical Building Code, CTE, 2013. Available online: http://www. codigotecnico.org/ (2017ko otsaila).

[64] Design Builder Simulation Tool. Available online: http://www.designbuilder.es (2017ko otsaila).

[65] Red Electrica de España. Availabale online: http://www.ree.es/en (2017ko otsaila). 
[66] Eurostat. Electricity and natural gas price statistics, 2014. Online data code: nrg_pc_202 and rg_pc_204 (2017ko otsaila).

[67] E-Control \& VaasaETT. Household Energy Price Index for Europe, 2015.

[68] Boverket \& MMR. National Board of Housing, Building and Planning, Sweden \& Ministry for Regional Development of the Czech Republic (Ed.), Housing Statistics in the European Union 2004.

[69] Ramesh, T., Prakash, R., Shukla, K.K. (2010). Life cycle energy analysis of buildings: An overview. Energy Build., 42, 1592-1600.

[70] Sharma, A., Saxena, A., Sethi, M., Shree, V. (2011). Life cycle assessment of buildings: A review. Renew. Sustain. Energy Rev., 15, 871-875.

[71] Crawford, R.H. (2008). Validation of a hybrid life-cycle inventory analysis method. J. Environ. Manag., 88, 496-506.

[72] Pettersen, T.D. (1994). Variation of energy consumption in dwellings due to climate, building and inhabitants. Energy Build., 21, 3, 209-218.

[73] Juodis, E., Jaraminiene, E, Dudkiewicz, E. (2009). Inherent variability of heat consumption in residential buildings. Energy Build., 41(11):1188-1194. 